INFÂNCIA E LEITURA 


\section{Por onde anda a louca da casa?}

Flávio Carneiro

Universidade Federal de Minas Gerais

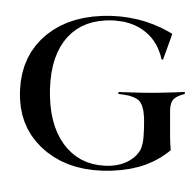

ostaria de começar com uma história, uma antiga lenda oriental, recontada por Malba Tahan. O título é "Uma fábula sobre a fábula" e narra o seguinte:

Allahur Akbar! Allahur Akbar! ${ }^{1}$

Quando Deus criou a mulher, criou também a Fantasia. Um dia, a Verdade resolveu visitar um grande palácio. E havia de ser o próprio palácio em que morava o sultão Harum Al-Raschid.

Envoltas as lindas formas num véu claro e transparente, foi ela bater à porta do rico palácio em que vivia o glorioso senhor das terras muçulmanas. Ao ver aquela formosa mulher, quase nua, o chefe dos guardas perguntou-lhe:

- Quem és?

- Sou a Verdade! - respondeu ela, com voz firme. - Quero falar ao vosso amo e senhor, o sultão Harum Al-Raschid, o cheique do Islã!

O chefe dos guardas, zeloso da segurança do palácio, apressou-se em levar a nova ao grão-vizir:

- Senhor - disse, inclinando-se humilde -, uma mulher desconhecida, quase nua, quer falar ao nosso soberano, o sultão Harum Al-Rashid, Príncipe dos Crentes.

- Como se chama?

- Chama-se a Verdade!

- A Verdade! - exclamou o grão-vizir, subitamente assaltado de grande espanto. - A Verdade quer penetrar neste palácio! Não! Nunca! Que seria de mim, que seria de todos nós, se a Verdade aqui entrasse? A perdição, a desgraça nossa! Dize-lhe que uma mulher nua, despudorada, não entra aqui!

Voltou o chefe dos guardas com o recado do grão-vizir e disse à Verdade: - Não podes entrar, minha filha. A tua nudez iria ofender o nosso califa. Com esses ares impudicos não poderás ir à presença do Príncipe dos

${ }^{1}$ Deus é grande! Deus é grande! 
Crentes, o nosso glorioso sultão Harum Al-Raschid. Volta, pois, pelos caminhos de Allah!

Vendo que não conseguiria realizar o seu intento, ficou muito triste a Verdade, e afastou-se lentamente do grande palácio do magnâmico sultão Harum Al-Raschid, cujas portas se fecharam à diáfana formosura! Mas...

Allahur Akbar! Allahur Akbar!

Quando Deus criou a mulher, também criou a Obstinação. E a Verdade continuou a alimentar o propósito de visitar um grande palácio. E havia de ser o próprio palácio em que morava o sultão Harum Al-Raschid... Cobriu as peregrinas formas de um couro grosseiro como os que usam os pastores e foi novamente bater à porta do suntuoso palácio em que vivia o glorioso senhor das terras muçulmanas.

Ao ver aquela formosa mulher grosseiramente vestida com peles, o chefe dos guardas perguntou-lhe:

- Quem és?

- Sou a Acusação! - respondeu ela, em tom severo. - Quero falar ao vosso amo e senhor, o sultão Harum Al-Raschid. Comendador dos Crentes.

O chefe dos guardas, zeloso da segurança do palácio, correu a entenderse com o grão-vizir.

- Senhor - disse, inclinando-se humilde -, uma mulher desconhecida, o corpo envolto em grosseiras peles, deseja falar ao nosso soberano, o sultão Harum Al-Raschid.

- Como se chama?

- A Acusação!

- A Acusação? - repetiu o grão-vizir, aterrorizado. - A Acusação quer entrar neste palácio? Não! Nunca! Que seria de mim, que seria de todos nós, se a Acusação aqui entrasse! A perdição, a desgraça nossa! Dize-lhe que não, não pode entrar! Dize-lhe que uma mulher, sob as vestes grosseiras de um zagal, não pode falar ao Califa, nosso amo e senhor!

Voltou o chefe dos guardas com a proibição do grão-vizir e disse à Verdade:

- Não podes entrar, minha filha. Com essas vestes grosseiras, próprias de um beduíno rude e pobre, não poderás falar ao nosso amo e senhor, o sultão Harum Al-Raschid. Volta, pois, em paz, pelos caminhos de Allah! Vendo que não conseguiria realizar o seu intento, ficou ainda mais triste a Verdade e afastou-se vagarosamente do grande palácio do poderoso Harum Al-Raschid, cuja cúpula cintilava aos últimos clarões do sol poente.

Mas...

Allahur Akbar! Allahur Akbar! 
Quando Deus criou a mulher criou também o Capricho.

E a Verdade entrou-se do vivo desejo de visitar um grande palácio. E havia de ser o próprio palácio em que morava o sultão Harum AlRaschid.

Vestiu-se com riquíssimos trajes, cobriu-se com jóias e adornos, envolveu o rosto em um manto diáfano de seda e foi bater à porta do palácio em que vivia o senhor dos Árabes.

Ao ver aquela encantadora mulher, linda como a quarta lua do mês de Ramadã, o chefe dos guardas perguntou-lhe:

- Quem és?

- Sou a Fábula - respondeu ela, em tom meigo e mavioso. - Quero falar ao vosso amo e senhor, o generoso Harum Al-Raschid, Emir dos Árabes! O chefe dos guardas, zeloso da segurança do palácio, correu, radiante, a falar com o grão-vizir:

- Senhor - disse, inclinando-se, humilde -, uma linda e encantadora mulher, vestida como uma princesa, solicita audiência de nosso amo e senhor, o sultão Harum Al-Raschid, Emir dos Crentes.

- Como se chama?

- Chama-se a Fábula!

- A Fábula! - exclamou o grão-vizir, cheio de alegria. - a Fábula quer entrar neste palácio! Allah seja louvado! Que entre! Bem-vinda seja a encantadora Fábula: Cem formosas escravas irão recebê-la com flores e perfumes. Quero que a Fábula tenha, neste palácio, o acolhimento digno de uma verdadeira rainha!

E abertas de par em par as portas do grande palácio de Bagdá, a formosa peregrina entrou.

E foi assim, sob o aspecto de Fábula, que a Verdade conseguiu aparecer ao poderoso califa de Bagdá, o sultão Harum Al-Raschid, Vigário de Allah e senhor do grande império muçulmano!

Das poucas leituras possíveis para esta fábula da fábula, gostaria de destacar uma: a ficção como disfarce da verdade.

Muito já se disse sobre a importância da fábula, dos contos de fadas e outras formas de narrativa afins para o pleno desenvolvimento da personalidade. A psicanálise, sobretudo, demonstra, de forma convincente, que a estrutura maniqueísta dos contos de fada ajuda a ordenar o universo infantil, contribuindo para a formação de parâmetros de comportamento que irão influenciar decisivamente o processo de amadurecimento. Não é

${ }^{2}$ TAHAN, 2002, p. 60-62. 
difícil, portanto, elencar os benefícios desses formatos diversos de histórias com fundo moralizante.

Acho importante, no entanto, lembrar também o outro lado, o do controle, o da manipulação ideológica que se apropria do ficcional e lhe empresta uma função que não lhe cabe: a de impôr a verdade. Vestida de ficção, a verdade (ou a acusação), entra pela porta da frente no reino do pequeno leitor, erguendo belos palácios, é certo, mas também provocando grandes estragos.

No breve ensaio "Velhos livros infantis", Walter Benjamin lembra que o livro infantil alemão nasce com o Iluminismo:

Com sua forma de educação os filantropos colocaram à prova o imenso programa de formação humanitário. Se o homem era piedoso, bom e sociável por natureza, então deveria ser possível fazer da criança, ser natural por excelência, o homem mais piedoso, mais bondoso e mais sociável. E como em todas as pedagogias teoricamente fundamentadas a técnica da influência objetiva só foi descoberta mais tarde e aquelas advertências problemáticas constituíam o início da educação, assim também o livro infantil tornou-se, nos primeiros decênios, moralista, edificante e variava o catecismo e exegese no sentido de deísmo. ${ }^{3}$

Benjamin não manda queimar esse primeiros livros infantis - pelo contrário, vê neles, no decorrer no ensaio, qualidades que faltam à moderna produção ficcional para crianças -, mas não esquece seu lado problemático. Tampouco é minha intenção condenar a fábula ou o conto de fadas, mas apenas buscar, neles, o princípio de um fio condutor que possar guiar esta fala.

Há nesse tipo de narrativa um convite ao imaginário na forma sedutora de situar a história num tempo e espaço distantes, com cenários, figurinos e personagens que, não por acaso, jamais sairão do terreno privilegiado de nossa fantasia. Mesmo adulto, ninguém resiste ao "era uma vez, num reino distante..." Mas há também, por outro lado, uma repressão a esse mesmo imaginário quando a ficção faz as vezes de mero transporte da ideologia.

Benjamin afirma que os erros dos primeiros livros infantis são mínimos se comparados com uma "suposta empatia com a natureza infantil, tão em voga hoje em dia". Segundo o filósofo, a "criança exige do adulto uma representação clara e compreensível, mas não 'infantil'”, e mais: "a criança tem um sentido aguçado mesmo para uma seriedade distante e grave,

${ }^{3}$ BENJAMIN, 1984, p. 49. 
contanto que esta venha sincera e diretamente do coração". ${ }^{4}$ Benjamin faz seu comentário nos anos 20. Imagine se lhe fosse dado ver o que viria mais tarde.

Comparado com as fábulas e os contos de fada tradicionais, o que vemos hoje é algo bem mais grave. A natureza ambígua dessas velhas histórias - a de serem, ao mesmo tempo, libertação e repressão do imaginário - desaparece, dando lugar a um processo violento de apropriação indevida da ficção, com vistas não apenas a uma repugnante propaganda ideológica como também a interesses puramente comerciais.

Em um artigo publicado há alguns anos atrás, "No jardim de Borges", desenvolvo, a partir de uma afirmação do escritor e ensaísta argentino Ricardo Piglia, um paralelo entre o ato da leitura e o trabalho do detetive. Na época, dizia que ler "é armar-se de lupa, cachimbo e chapéu, como um Sherlock, e sair atrás das pistas que, evidentes ou sutis, verdadeiras ou falsas, o texto vai deixando pelo caminho." 5

Pois gostaria de convocar todos vocês, leitores-detetives, agora e nos dias que se seguem, a investigar um crime. Trata-se de um seqüestro. Mais exatamente, do seqüestro de uma louca. A escritora espanhola Rosa Montero chamou seu último livro, recém-publicado no Brasil, de "A louca da casa." Título que Rosa foi buscar numa frase de Santa Teresa de Jesus: "a imaginação é a louca da casa." Nessa seqüência de pequenos furtos lícitos - o que é a literatura senão uma saudável pilhagem da biblioteca alheia? -, tomo emprestado de Rosa Montero o título que ela tomou de empréstimo a Santa Teresa para convidá-los a investigar esse complicado seqüestro, que se arrasta já por algum tempo e tem tomado dimensões assustadoras.

Peço desculpas por já ter dado início aos trabalhos. E o fiz invertendo a pergunta, de modo, quem sabe, a melhor respondê-la. Refeita, a pergunta ficou: por onde não anda a louca da casa? Talvez possamos não encontrála nos contos de fada, nas fábulas, embora parte dela, seu perfume quem sabe, ainda esteja lá.

Certamente não iremos encontrá-la num livro de Paulo Coelho. Aliás, um outro título pensado para esta conferência foi: "Por que não gosto de Paulo Coelho" (entenda-se, claro, o escritor e não a pessoa). Não gosto de Paulo Coelho porque gosto da literatura. Não gosto de Paulo Coelho

\footnotetext{
${ }^{4}$ BENJAMIN, 1984, p. 50.

${ }^{5}$ CARNEIRO, p. 69.
} 
porque, como Bartolomeu Campos Queiroz, acredito que a "fantasia é o que há de mais íntimo em nós", ${ }^{6}$ e não posso gostar de ver alguém vendendo intimidades pré-fabricadas.

O motivo de eu não gostar de Paulo Coelho não é o fato de ele veicular sabedoria de almanaque, vendendo como erudição o que é apenas uma versão facilitada de conceitos complexos, tomados de empréstimo a filosofias diversas. Claro, também não gosto disso, mas o problema maior, a meu ver, não é esse.

O problema maior, mais grave, é Paulo Coelho ser vendido como ficção. Como a escola européia, de feição iluminista, se apropriou das narrativas orais para veicular ideologia, através dos contos de fada, como os primeiros missionários portugueses se apropriaram do teatro popular, através dos autos, para catequizar nossos índios, a obra de Paulo Coelho se apropria indevidamente do poder sedutor de um antigo modo de se contar histórias para veicular máximas da chamada "literatura de auto-ajuda".

Quando esse tipo de estratégia funciona, a ficção morre. Quando a ficção morre, morre sempre um pouco a imaginação. Quem leu Peter Pan sabe que quando uma criança diz: não acredito em fadas, uma fada morre instantaneamente. Mas há outras formas de se matar uma fada. Por exemplo, se utilizando dela para instaurar não a diferença - condição de existência de qualquer ficção autêntica - mas a norma.

O maniqueísmo, a moral da história - condições de existência de qualquer pseudo-ficção - é uma arma mortífera contra as fadas. Todas essas pseudo-ficções contemporâneas - como várias dessas coleções de histórias infantis feitas sob encomenda para antender a certas fatias do mercado são serial killers de fadas. Paulo Coelho é um serial killer de fadas.

Confesso que não sei qual dos dois é mais letal: doses maciças de Paulo Coelho ou livros de auto-ajuda para criancças. Sim, eles existem. Diga-se de passagem, foi por ter lido uma matéria sobre eles na revista Veja, de 15 de setembro desse ano, que decidi dar o rumo que dei a esta conferência. O título da matéria é "Para estressados mirins" e o primeiro parágrafo diz o seguinte:

A literatura sempre foi uma arma poderosa dos pais para transmitir valores morais e éticos a seus filhos. Todos os clássicos da ficção infantil trazem exemplos do que é bom e do que é mau, do certo e do errado, e terminam com a mensagem de que é possível superar medos, traumas

${ }^{6}$ QUEIRÓS, 2004, p. 3. 
e diferenças. De uns tempos para cá, um outro tipo de livro passou a concorrer com a turma do Pinóquio e da Cinderela - o de auto-ajuda infantil. Isso mesmo: também as crianças se tornaram alvo dos manuais que fornecem fórmulas práticas para resolver todos os problemas da vida. Enquanto a ficção infantil convencional utiliza fantasias e metáforas para transmitir suas lições, os livros de auto-ajuda vão direto ao ponto. Ensinam a criança a lidar com o divórcio dos pais e não se sentir culpada pela separação, mostram como superar a morte de pessoas queridas, como se sair bem na escola e até como ser gordinho num mundo em que Felipe Dylon e Gisele Bündchen são o padrão de beleza. ${ }^{7}$

Mais adiante, a matéria diz o que o leitor já terá adivinhado:

Como já acontece há tempos com seus equivalentes para adultos, os livros de auto-ajuda infantil estão se tornando um fenômeno editorial. Nos Estados Unidos, a venda de títulos do gênero duplicou nos últimos doze meses. No Brasil, calcula-se que tenha aumentado 50\% em 2003. 'A procura nos pressionou a criar um selo só para essa categoria', diz a paulista Lenice Bueno, da editora Salamandra, há 25 anos especializada em obras infantis. ${ }^{8}$

A escrita e a leitura que se prestam a esse jogo de cartas marcadas são, antes de mais nada, fascistas. No romance Em liberdade, Silviano Santiago cria um falso diário de Graciliano Ramos e, através desse engenhoso recurso, vai lançando recados que, sob a falsa voz de Graciliano, dirigem-se sobretudo aos contemporâneos de Silviano. Um desses recados deixa bem claro que ler e escrever são atos que só funcionam se desvinculados de qualquer busca de uma verdade única. E ainda: que o cerceamento do imaginário, através de uma estratégia de estabelecimento do consenso, e não da diferença, é a pior das formas de opressão. Diz o diário fictício de Graciliano, escrito por Silviano Santiago:

A verdadeira leitura é uma luta entre subjetividades que afirmam e não abrem mão do que afirmam, sem as cores da intransigência. O conflito romanesco é, em forma de intriga, uma cópia do conflito da leitura. Ficção só existe quando há conflito, quando forças diferentes digladiamse no interior do livro e no processo de sua circulação pela sociedade. Encontrar no romance o que já se esperava encontrar, o que já se sabe,

\footnotetext{
${ }^{7}$ REVISTA VEJA, 2004, p. 127.

${ }^{8}$ REVISTA VEJA, 2004, p. 127.
} 
é o triste caminho de uma arte fascista, onde até mesmo os meandros e os labirintos da imaginação são programados para que não haja a dissidência do pensamento. ${ }^{9}$

Durante alguns anos, integrei a equipe que planejou e executou a primeira versão do PROLER (Programa Nacional de Incentivo à Leitura, da Biblioteca Nacional), sob coordenação de Eliana Yunes. Antes e depois disso, em oficinas, aulas, palestras, sempre defendi a idéia de que não se deve discriminar nenhum tipo de leitura quando se trata de leitores iniciantes. Com o tempo, pensava, o leitor vai se sofisticando, e se no início lia Sabrina e Bianca, futuramente chegará a textos mais sofisticados.

Hoje, no entanto, não diria que mudei de idéia, mas já não defendo a tese com a mesma convicção. Começo, até, a desconfiar de que Schopenhauer tinha razão quando afirmava o seguinte: "com relação a nossas leituras, a arte de não ler é sumamente importante (...) Para ler o bom uma condição é não ler o ruim: porque a vida é curta e o tempo e a energia escassos." ${ }^{10}$

E o dinheiro também, acrescentaria. Um editor já disse, certa vez, que no Brasil, infelizmente, quando se compra um livro deixa-se de comprar outro. E se não há espaço para todos, sejamos aprendizes da difícil arte de não ler. Se nosso exercício de investigação não chegou ainda a detectar o lugar, ou os lugares, onde foi parar a louca da casa, que saibamos pelo menos evitar os lugares onde ela não está.

O lingüista francês Vincent Jouve, num pequeno livro intitulado "A leitura", observa:

É (...) a criança que fomos que permite acreditar nas narrativas romanescas. Havia uma época em que reinava a lenda, em quer o ser e o parecer não se distinguiam (quem nunca acreditou em Papai Noel?). Esse consentimento eufórico na ficção nunca desaparece totalmente (nossa relação com a figura de Papai Noel sobrevive à tomada de consciência de sua ficcionalidade). Nossas crenças infantis, reativadas em certas condições (entre elas a situação de leitura), subentendem nossas crenças de adultos. Assim que abrir um romance, é a criança que renasce (pelo menos em certo nível). ${ }^{11}$

\footnotetext{
9 SANTIAGO, 1981, p. 117.

${ }^{10}$ SCHOPENHAUER, 1994, p.33 e 35.

${ }^{11}$ JOUVE, 2002, p. 117.
} 
Logo a seguir, Jouve cita Michel Picard:

A criança persiste dentro de nós e assina: é ela que, aí, é o jogado, o lido, depreendido das leis do Logos e das categorias do espaço-tempo; é na sua credulidade inocente que, hipocritamente, a tolerância do ledor, aqui e agora, se junta à ilusão. A criança serve de suporte e de álibi para a credulidade do adulto: assim reencontramo-la como mediador interno, herói, testemunha ou narrador, em numerosas ficções, e em particular no Fantástico, onde freqüentemente lhe é atribuída uma função mista de vítima e de fiador: em $O$ homem de areia ou A volta do parafuso, por exemplo. ${ }^{12}$

Por fim, o autor relembra Grivel, que escreveu, no final dos anos 80, o seguinte:

Que idade temos quando lemos? ... Respondo: a primeira idade! É quando criança que lemos, do ângulo da primeira vez e obcecados por ela. Primeiro ponto: minha paixão. Ler é um desejo de infância. Doarse para o texto, pelo deciframento do olhar ou da pena, é sonhar com uma capacidade anterior, com uma frescura desaparecida, com um desatino do imaginário cuja idéia se fixou logo no início da vida consciente. ${ }^{13}$

A conclusão deste fragmento do livro de Vincent Jouve merece nossa atenção. Diz ele: "A leitura é, antes de mais nada, uma desforra da infância." ${ }^{4}$

Desforra contra o quê?, poderíamos perguntar. Talvez contra a sistemática anulação do imaginário que lhe foi imposta no correr do tempo, e que anseia vir à tona num mundo onde se imagina cada vez menos.

Machado de Assis, num texto publicado em 1882, comentava o lançamento do livro "Contos seletos das mil e uma noites", organizado por Carlos Jansen. Ao final do seu comentário, Machado observa:

Esquecia-me que o livro é para adolescentes, e que estes pedem-lhe, antes de tudo, interesse e novidades. Um descedentes de teutões contalhes pela língua de Alencar e Garrett umas histórias mouriscas: com

${ }^{12}$ JOUVE, 2002, p. 117.

${ }^{13}$ JOUVE, 2002, p. 118.

${ }^{14}$ JOUVE, 2002, p. 117. 
aquele operário, este instrumento e esta matéria, dá-lhe o Sr. Laemmert, velho editor incansável, um brinquedo graciosíssimo, com que podem entreter algumas horas dos seus anos em flor. Sobra-lhes para isso a ingenuidade necessária; e a ingenuidade não é mais que a primeira porção do ungüento misterioso, cuja história é contada nestas mesmas páginas. Esfregado na pálpebra esquerda de Abdallah, deu-lhe espetáculo de todas as riquezas da terra; mas o pobre-diabo era ambicioso, e, para possuir o que via, pediu ao derviche que lhe ingisse também a pálpebra direita, com o que o cegou de todo. Creio que esta outra porção do ungüento é a experiência. Depressa, moços, enquanto o derviche não unge a outra pálpebra! $!^{15}$

É justamente essa "ingenuidade necessária" citada por Machado que revive quando abrimos um romance. Sem ela não há possibilidade de leitura, de inserção no mundo de papel e tinta, tão fundamental quanto o outro. É natural que essa mesma ingenuidade vá se perdendo com o tempo, como preço que pagamos pelo crescimento, mas é fundamental também que ela renasça sob outras formas na vida adulta. Para isso serve a literatura, para nos fazer lembrar que um dia acreditamos na fantasia. É esta a sua única e primordial função, e qualquer outra é não apenas desnecessária como extremamente perigosa.

Se a criança que fomos é reencontrada a cada vez que lemos um romance, é também sufocada a cada vez que lemos qualquer ficção falsa. É preciso estar atento para o embuste, a enganação. Falsa é a ficção que se presta a qualquer interesse que não seja unicamente o de despertar o imaginário do leitor, de libertar a louca da casa, trancafiada nos escritórios, nos gabinetes, nos shopping centers, às vezes na sala-de-aula e, claro, nos próprios livros que supostamente deveriam libertá-la.

Lembro um poema de Oswald de Andrade, intitulado "3 de maio":

Aprendi com meu filho de dez anos

Que a poesia é a descoberta

Das coisas que nunca vi. ${ }^{16}$

Também Gabriel, de seis anos, filho da minha mulher, recentemente me deu uma aula sublime sobre o conceito de poesia. Eu me despedia dele, de manhã, para ir ao Rio, dar aula, e disse: "Tchau, Biba, até de noite." Depois

\footnotetext{
${ }^{15}$ ASSIS, 1994, p. 919.

${ }^{16}$ ANDRADE, 1971, p. 104.
} 
me lembrei de que naquele dia chegaria mais tarde em casa, quando talvez ele já estivesse dormindo, e por isso consertei: "Quer dizer, até de noite ou até amanhã, não sei..." E ele, de pronto, respondeu: "Então faz assim: me dá um tchau sem fundo."

Claro que qualquer comentário sobre a frase de Gabriel seria uma violência, um crime de lesa-poesia.

Digo apenas que sua frase me fez lembrar a de uma outra criança, que não cheguei a conhecer pessoalmente. Era uma menina, me parece que cursava a quarta ou quinta série, aluna de um amigo meu. Esse amigo havia pedido que seus alunos escrevessem uma redação com o tema: "Meu maior sonho." Pois essa menina, diante da folha em branco, escreveu apenas uma frase: "Meu maior sonho é poder realizá-lo."

Como a frase de Gabriel, esta também não merece a violência de ser desvendada, e deixo-a depositada aqui, sem mais, apenas como se deposita no estojo uma pequena pérola.

E deixo também, para vocês, um outro presente, fruto da imaginação de Millôr Fernandes, que no seu adorável Fábulas fabulosas reescreve antigas histórias, desmontando por dentro qualquer estrutura maniqueísta, de modo a criar sempre o inusitado. É justamente nesse terreno, o da afirmação da diferença, que Millôr constrói suas novas velhas fábulas, apostando não na doutrinação do leitor mas na sua capacidade de pensar e imaginar.

Dessas fábulas fabulosas, recortei a que se segue, intitulada "O rei dos animais":

Saiu o leão a fazer sua pesquisa estatística, para verificar se ainda era o Rei das Selvas. Os tempos tinham mudado muito, as condições do progresso alterado a psicologia e os métodos de combate das feras, as relações de respeito entre os animais já não eram as mesmas, de modo que seria bom indagar. Não que restasse ao Leão qualquer dúvida quanto à sua realeza. Mas assegurar-se é uma das constantes do espírito humano e, por extensão, do espírito animal. Ouvir da boca dos outros a consagração do nosso valor, saber o sabido, quando ele nos é favorável, eis um prazer dos deuses. Assim o Leão encontrou o Macaco e perguntou: "Hei, você aí, Macaco - quem é o rei dos animais?" O Macaco, surpreendido pelo rugir indagatório, deu um salto de pavor e, quando respondeu, já estava no mais alto galho da mais alta árvore da floresta: "Claro que é você, Leão, claro que é você!"

Satisfeito, o Leão continuou pela floresta e perguntou ao papagaio: "Currupaco, papagaio. Quem é, segundo seu conceito, o Senhor da Floresta, não é o Leão?" E como aos papagaios não é dado o dom de 
improvisar, mas apenas o de repetir, lá repetiu o papagaio: "Currupaco... não é o Leão? Não é o Leão? Currupaco, não é o Leão?”

Cheio de si, o Leão prosseguiu em busca de novas afirmações de sua personalidade. Encontrou a coruja e perguntou: "Coruja, não sou eu o maioral da mata?" "Sim, és tu", disse a coruja. Mas disse de sábia, não de crente. E lá se foi o Leão, mais firme no passo, mais alto de cabeça. Encontrou o Tigre. "Tigre" - disse em voz de estentor - "eu sou o rei da floresta. Certo?" O Tigre rugiu, hesitou, tentou não responder, mas sentiu o barulho do olhar do Leão fixo em si, e disse, rugindo contrafeito: "Sim." E rugiu ainda mais mal humorado e já arrependido, quando o Leão se afastou.

Três quilômetros adiante, numa grande clareira, o Leão encontrou o Elefante. Perguntou: "Elefante, quem manda na floresta, quem é Rei, Imperador, Presidente da República, dono e senhor de árvores e de seres, dentro da mata?" O elefante pegou-o pela tromba, deu três voltas com ele pelo ar, atirou-o contra o tronco de uma árvore e desapareceu floresta adentro. O Leão caiu no chão, tonto e ensangüentado, levantou-se lambendo uma das patas, e murmurou: "Que diabo, só porque não sabia a resposta não era preciso ficar tão zangado".

MORAL: CADA UM TIRA DOS ACONTECIMENTOS A CONCLUSÃO QUE BEM ENTENDE. ${ }^{17}$

Antes de concluir esta investigação precária, talvez fosse o caso de ao menos lembrar alguns lugares da produção literária brasileira para crianças e jovens que têm servido, já faz algum tempo, como moradia da louca. São casas em que a imaginação ainda resiste bravamente à incursão de invasores que, trazendo à mão camisas-de-força, tentam de todo modo aquietá-la. Refiro-me aos livros de Bartolomeu Campos Queiróz, Ângela Lago, Roger Melo, Rui de Oliveira, Ziraldo, Luciana Sandroni, Roseana Murray e, claro, Lygia Bojunga. A relação é bem modesta, reconheço, e naturalmente incompleta, mas sua intenção é apenas deixar registrada algumas de minhas andanças de leitor-detetive. Feliz da literatura que conta com nomes como estes, mestres, e sempre aprendizes, da escrita e do desenho para crianças e jovens.

Gostaria de encerrar minha fala com outro autor de minha biblioteca de afeição, um autor que soube criar diversas moradas para a louca da casa, instalando-a em cidades diversas, algumas invisíveis. Trata-se de Italo Calvino, que, numa de suas propostas para o próximo milênio, a de número

17 FERNANDES, 1963, p. 13-14. 
quatro: visibilidade, diz o seguinte: "a imaginação é um lugar dentro do qual chove." 18

No milênio que se inicia, talvez devêssemos também lançar nossas propostas. Cada qual lance a sua, e gostaria desde já de deixar também a minha - uma proposta um tanto vaga, eu sei, mas bastante sincera. Que façamos chover muito. Que as águas levem de vez, numa enxurrada, toda forma perversa de apropriação do imaginário, toda pseudo-ficção que se procura vender como pílula mágica para adultos e crianças, e que essas mesmas águas tragam antigas e novas fantasias, capazes de garantir o exercício da imaginação, única garantia de futuro para quem ainda acredita em fadas.

\section{Referências Bibliográficas}

ANDRADE, Oswald de. Poesias reunidas. 5. ed. Rio de Janeiro: Civilização Brasileira, 1971, pág. 104.

ASSIS, Machado. Obra completa. Rio de Janeiro: Nova Aguilar, 1994. V. III.

BENJAMIN, Walter. Reflexões: a criança, o brinquedo, a educação. 3. ed. Trad. Marcus Vinicius Mazzari. São Paulo: Summus, 1984.

CALVINO, Italo. Seis propostas para o próximo milênio. Trad. Ivo Barroso. São Paulo: Companhia das Letras, 1991.

CARNEIRO, Flávio. No jardim de Borges, Matraga, Rio de Janeiro, v. 1, n. 9 , p. 69-80, ago. 1997.

FERNANDES, Millôr. Fábulas fabulosas. Rio de Janeiro: Nórdica, 1963.

JOUVE, Vincent. A leitura. Trad. Brigitte Hervot. São Paulo: UNESP, 2002.

MONTERO, Rosa. A louca da casa. Trad. Paulina Wacht e Ari Roitman. Rio de Janeiro: Ediouro, 2004.

OSWALD, Mário. Poesias reunidas. 5. ed. Rio de Janeiro: Civilização Brasileira, 1971.

QUEIRÓS, Bartolomeu Campos. Não gosto de literatura com destinatário, Jornal do Brasil (Caderno Idéias), Rio de Janeiro, 18 set. 2004.

${ }^{18}$ CALVINO, 1991, p. 97. 
Revista Veja - São Paulo, no 37, 15 set. 2004, p. 127.

SANTIAGO, Silviano. Em liberdade. Rio de Janeiro: Paz e Terra, 1981.

SCHOPENHAUER, Arthur. Sobre livros e leitura. Trad. Phillippe Humblé e Walter Carlos Costa. Porto Alegre: Paraula, 1994.

TAHAN, Malba. Minha vida querida. Rio de Janeiro: Conquista, 1957.

\section{Resumo}

Anunciamos um seqüestro e propomos uma investigação detetivesca: por onde anda, ou por onde não anda, a imaginação? Parte-se de uma premissa: desde os seus primórdios, a literatura, para crianças e adultos, tem servido tanto como instrumento de abertura quanto de repressão do imaginário. Das várias formas de fascismo, talvez a mais cruel seja aquela que toma emprestadas as armas de sedução do texto literário para anunciar falsas promessas de liberdade, vetando a imaginação quando parece franqueá-la. Daí a importância, hoje, de se perguntar: não seria o caso de nos dedicarmos às vezes à delicada arte de não ler?

\section{Résumé}

Nous annonçons un enlèvement et proposons une investigation de détective où se trouve l'imagination? où n'est-elle pas? On part d'une prémisse: a début, la littérature pour enfants et pour adultes fonctionne comme un instrument de liberté aussi bien que de répression de l'imaginaire. Parmi plusieurs formes de fascisme, la plus cruelle est peutêtre celle que se sert des armes de séduction du texte littéraire pour annoncer de fausses promesses de liberté, détenant l'imagination au même temps qu'elle semble la libérer. D'où l'importance, aujourd'hui, de la question: ne faudrait-il pas nos adonner parfois à l'art de ne pas lire? 